\title{
Canadian clinicians and patients need clean, clear knowledge
}

$\mathrm{C}$ lean water played a vitally important part in controlling the infections of the communicable diseases that ravaged Europe in the igth and 2oth centuries. These diseases still impair the health of people living in developing countries. Today it is evident that, even in developed countries such as Canada, the epidemics of the 2ist century cannot be prevented or controlled, despite our access to clean water. However, there is good evidence that they can be controlled by the provision of clean, clear knowledge. This knowledge ideally will be centralized and made available through a national library of health.

By applying what we know from research, from experience and from the analysis of data, we can either minimize or prevent several major health care problems:

- Errors

- Poor-quality health care

- Patients with negative experiences

- Variations in policy and practice

- Wasting of resources

- Overenthusiastic adoption of low-value interventions

- Failure to get new, high-value interventions into practice. Not only do people in developed countries, patients and health care professionals alike, need clear knowledge, they have a right to that knowledge. Ignorance is like cholera it cannot be controlled by the individual alone. Addressing ignorance requires the organized efforts of society and can be seen as a public health responsibility.

In providing clean, clear knowledge, the first step is to purify the knowledge. The excellent work produced by the Health Informatics Research Unit at McMaster University (including the evidence-based journals ACP Journal Club, Evidence-based Medicine and Evidence-based Nursing) and the Chalmers Research Group in Ottawa has demonstrated the flaws in the peer review system. Measures are needed to reduce errors based on bias and chance in the scientific literature. This quality-assured knowledge needs to be made accessible by means of a network to the people who can use it. Furthermore, knowledge, like water, may need to be pumped with energy to ensure that it reaches the people who can use it. There is no point in leaving water lying in a reservoir, hoping that people will make their own way there with their buckets. A library is a conduit of knowledge, ensuring that the properly formulated information reaches clinicians and patients at a time of need.

The health community in Canada has given so much to the world in the work it has done to develop librarianship and quality assurance of clinical knowledge. The evidence-based movement - developed and led by David Sackett and now continuing in Hamilton (with Brian Haynes at McMaster University) and Toronto (with Sharon Straus at the University of Toronto) - helps the user of knowledge, whether patient or clinician, decide how best to apply that knowledge for the individual patient. But, before one is able to use clear knowledge, it has to be made easily available.

I have watched with admiration and have benefited from Canadian developments, from the introduction of evidencebased medicine to the advances in knowledge translation and implementation. It has always seemed paradoxical that Canada, a country that is the fount of so much good work in these areas, does not have a national library. No new building is needed; simply a national network using the tools that are made available through the e-health revolution. Creation of the Canadian Health Libraries Association's proposed National Network of Libraries for Health (www.chla-absc.ca /nnlh) would allow for coordinated, centralized access to evidence-based knowledge as well as support by librarians to all health care providers, researchers and policy-makers, regardless of their location or institutional affiliation. This network will capitalize on existing resources and networks. ${ }^{1}$ We look forward to learning from yet another Canadian initiative.

\section{Sir J.A. Muir Gray}

Director of Clinical Knowledge, Process and Safety

University of Oxford

Director of the National Library for Health

and of the National Screening Committee, and Project Manager for the National Public Health Network Project Oxford, UK

\section{REFERENCE}

I. McGowan J, Straus SE, Tugwell P. Canada urgently needs a national network of libraries to access evidence. Healthc Q 2006;9:72-4, 4 . 